\title{
A PROTEÇÃO AO DIREITO FUNDAMENTAL À PRESERVAÇÃO DA CULTURA INDÍGENA À LUZ DA CONSTITUIÇÃO FEDERAL E DA SUPRALEGALIDADE DOS TRATADOS INTERNACIONAIS DE DIREITOS HUMANOS
}

\author{
PROTECTING THE FUNDAMENTAL RIGHT TO PRESERVATION OF \\ INDIGENOUS CULTURE IN THE LIGHT OF THE FEDERAL CONSTITUTION \\ AND SUPRA-LEGAL OF INTERNATIONAL TREATIES HUMAN RIGHTS
}

${ }^{1}$ Amanda Lima Gomes Pinheiro

\section{RESUMO}

O presente artigo tem por objetivo analisar a proteção ao direito fundamental à preservação da cultura indígena à luz da Constituição Federal e da supralegalidade dos tratados internacionais. A Constituição Federal de 1988 inovou ao dispor de uma extensa gama de direitos e garantias fundamentais espalhados por todo o seu texto, sem excluir os direitos fundamentais não expressos na Constituição, mas decorrentes dos princípios ou do regime por ela adotado, assim como aqueles contidos em tratados internacionais dos quais o Estado brasileiro seja parte. A Constituição se preocupou ainda em proteger os grupos minoritários (índios, mulheres, deficientes físicos, crianças, idosos) com a finalidade de garantir a igualdade material e corrigir eventuais situações de injustiças e desigualdades. Em que pese fazerem parte desse grupo minoritário protegido constitucionalmente, os povos indígenas continuam sendo violentados física e culturalmente. Verifica-se a partir da análise da decisão emanada pela Justiça Federal do Amazonas que a construção da Rodovia Transamazônica conduziu à desestruturação étnica dos povos indígenas, à homogeneização de culturas, à divisão de territórios e provocação de tensões entre etnias indígenas, em uma nítida afronta ao princípio da dignidade da pessoa humana, fundamento constitucional

Palavras-chave: Direitos fundamentais, Direitos humanos, Cultura indígena, Tratados internacionais, Supralegalidade

\begin{abstract}
This article aims to examine the protection of the fundamental right to the preservation of indigenous culture in the light of the Constitution and international treaties. The Federal Constitution of 1988 broke new ground by providing an extensive range of fundamental rights and guarantees scattered throughout his text, without excluding the fundamental rights not expressed in the Constitution, but flowing from the principles or rules adopted by it, as
\end{abstract}

\footnotetext{
${ }^{1}$ Mestre em Direito Constitucional, Especialista em Direito Processual pela Universidade Anhanguera, São Paulo. SP, Brasil. Email: indexlaw.ojs@ hotmail.com
} 
well as those contained in international treaties to which the Brazilian State is a party. However, indigenous peoples continue to be abused physically and culturally. It appears from the analysis of the decision issued by the Federal Court of the Amazon that the construction of the Trans-Amazon Highway led to the ethnic breakdown of indigenous peoples, the homogenization of cultures, the division of territories and provoking tensions between indigenous groups.

Keywords/Palabras-claves/Mots-clés: Fundamental rights, Human rights, Indigenous culture, International treaties, Supra-legal 


\section{INTRODUÇÃO}

O presente trabalho tem como foco analisar a proteção ao direito fundamental à preservação da cultura indígena à luz da Constituição Federal e da supralegalidade dos tratados internacionais de direitos humanos. Para alcançá-lo, desenvolveu-se pesquisa do tipo bibliográfica em trabalhos publicados sob a forma de livros, revistas, artigos, enfim, publicações especializadas, imprensa escrita e dados oficiais publicados na internet, que abordem direta ou indiretamente o tema em análise, e de natureza qualitativa por buscar apreciar a realidade do tema no ordenamento jurídico pátrio. Quantos aos fins, a pesquisa é exploratória, objetivando aprimorar as ideias através de informações sobre o tema em foco. Segundo a utilização dos resultados, é pura, à medida que teve como único fim a ampliação dos conhecimentos.

Dessa forma, inicialmente será apresentada a definição e a distinção entre os direitos fundamentais e os direitos humanos, logo após uma análise dos direitos fundamentais indígenas, com foco no direito à preservação da cultura indígena. Seguidamente, será brevemente desenvolvida análise da decisão paradigma à luz dos preceitos constitucionais e dos tratados internacionais. Finalmente, uma conclusão do trabalho será relatada.

\section{Direitos Fundamentais e Direitos Humanos - Definição e Distinção}

A ideologia cristã e a concepção dos direitos naturais foram os principais responsáveis pelo reconhecimento dos direitos fundamentais. Segundo o ensinamento de Lopes (2001, p.174), os direitos fundamentais tiveram o seu surgimento com o Estado Constitucional no século XIX, derivados da própria evolução humana, como resultado de um complexo de eventos. Ensina ainda que como normas principiológicas que legitimam o Estado, os direitos fundamentais devem refletir o sistema de valores do homem e sua dignidade e não mais transparecer que a dignidade da pessoa está associada a uma essência pelo simples fato de ser humano, o Estado tem a obrigação de satisfazer as necessidades de todos os membros, como forma de garantir efetividade dos direitos constitucionais. Nas palavras de LOPES: 
Os direitos fundamentais, como normas principiológicas legitimadoras do Estado - que traduzem a concepção da dignidade humana de uma sociedade - , devem refletir o sistema de valores ou necessidades humanas que o homem

precisa satisfazer para ter uma vida condizente com o que ele é. Com efeito, os direitos fundamentais devem exaurir a ideia de dignidade humana, porém não mais uma ideia de dignidade associada a uma natureza ou essência humana entendida como um conceito unitário e abstrato, mas como o conjunto de valores ou necessidades decorrentes da experiência histórica concreta da vida prática e real. Desse modo, os direitos fundamentais tornamse os mais adequados instrumentos legitimadores do Estado, já que a justificação do domínio e do poder estatal dependerá não só da forma como esses interesses universalizáveis (cujo conteúdo material são as necessidades humanas) estejam positivados - direitos fundamentais - mas, sobretudo, do grau de eficácia que tais direitos tenham. Falar de direitos fundamentais, então, não significa apenas fazer menção ao catálogo de direitos constitucionalizados, relativos à dignidade humana, mas significam verificar a idoneidade do Estado para satisfazer as necessidades de todos os membros que o compõem. (2001, p. 182)

Os direitos fundamentais, portanto, podem ser definidos como normas constitucionais de caráter principiológico, que traduzem a concepção de dignidade humana de cada sociedade e objetivam legitimar o poder jurídico-estatal. ${ }^{1}$

Hodiernamente, é inconcebível a existência de um Estado Democrático de Direito que não discipline os direitos fundamentais. A partir do surgimento e, também, da evolução de várias declarações de direitos (entre as várias existentes, a mais conhecida é a Declaração de Direitos do Homem e do Cidadão, de 16 de agosto de 1789, ainda em vigor na França), muitas Constituições passaram a adotar expressamente um rol de direitos fundamentais, como é o caso da Constituição da República Federativa do Brasil, que em seu Título II elenca os Direitos e Garantias Fundamentais.

Nesse momento, é necessário que se faça a distinção entre direitos humanos e direitos fundamentais. Embora usados como sinônimos, os direitos humanos e os direitos fundamentais se diferenciam. Segundo leciona José Joaquim Gomes Canotilho (2008), os direitos fundamentais são "os direitos do homem, jurídico-institucionalmente garantidos e limitados espacio-temporalmente", enquanto que os direitos humanos, ou direitos do homem, como gênero humano, são "direitos válidos para todos os povos e em todos os tempos".

Assim, Bidart Campos (1992) dispõe que "los derechos humanos, uma vez transvasados a la normativa constitucional, se convierten em derechos fundamentales". No 
mesmo sentido, Perez Luño (2007) esclarece a diferença dos termos direitos humanos e direitos fundamentais, onde direitos humanos seriam entendidos como um conjunto de

${ }^{1}$ LOPES, Ana Maria D’Ávila. Os Direitos Fundamentais como limites ao poder de legislar. Porto Alegre: Fabris, 2001.

faculdades e instituições que em cada momento histórico realizam a concretização das exigências da dignidade, ao passo que os direitos fundamentais seriam os direitos garantidos pela constituição e legislação, senão vejamos:

En los usos lingüísticos jurídicos, políticos e incluso comunes de nuestro tiempo, el término "derechos humanos" aparece como un concepto de contornos más amplios y imprecisos que la noción de "los derechos fundamentales". Los derechos humanos, suelen venir entendidos como un conjunto de facultades e instituciones que, en cada momento histórico, concretan las exigencias de la dignidad, la libertad y la igualdad humanas, las cuales deben ser reconocidas positivamente por los ordenamientos jurídicos a nivel nacional e internacional. En tanto que con la noción de los derechos fundamentales se tiende a aludir a aquellos derechos humanos garantizados por los ordenamientos jurídicos positivos en la mayor parte de los casos en su normativa constitucional, y que suelen gozar de una tutela reforzada. Los derechos humanos aúnan, a su significación descriptiva de aquellos derechos y libertades reconocidos en las declaraciones y convenciones internacionales, una connotación prescriptiva o deontológica, al abarcar también aquellas exigencias más radicalmente vinculadas al sistema de necesidades humanas, y que debiendo ser objeto de positivación no lo ha sido. Los derechos fundamentales poseen un sentido más preciso y estricto, ya que tan solo describen en conjunto de derechos y libertades jurídica y institucionalmente reconocidos y garantizados inste por el derecho positivo. Se trata, siempre, por tanto, de derechos delimitados espacial y temporalmente, cuya denominación responde a su carácter básico y fundamentador del sistema jurídico político del estado de derecho. (PEREZ LUÑO, 2007, p. 46-47)

Ainda sobre o tema, Lopes (2001, p. 41) traça a distinção entre as expressões, e enfatiza que são instituições diferentes, ou seja, direitos humanos são os princípios que resumem a concepção de uma convivência digna, livre e igual aos seres humanos, todavia os direitos fundamentais são direitos garantidos na constituição com limitação espacial e temporariamente.

A respeito do aspecto terminológico, a Constituição de 1988 apresenta diversas expressões em seu texto, como: “direitos humanos" (norma do artigo 4", II); “direitos e garantias fundamentais" (Título II e norma do artigo $5^{\circ}, \S 1^{\circ}$ ); direitos e liberdades constitucionais" (norma do artigo 5 $5^{\circ}, \mathrm{LXXI}$ ) e "direitos e garantias individuais" (norma do artigo $\left.60, \S 4^{\circ}, \mathrm{IV}\right)$. 
Importante destacar que os direitos fundamentais formam um dos pilares do princípio do Estado Democrático de Direito (ao lado da juridicidade e da constitucionalidade) ${ }^{2}$, concedendo legitimidade ao regime político-democrático. Em

\footnotetext{
${ }^{2}$ Independentemente das densificações e concretizações que o princípio do Estado de Direito encontra implícita ou explicitamente no texto constitucional, é possível sintetizar os pressupostos materiais subjacentes a este princípio da seguinte forma: 1) juridicidade; 2) constitucionalidade; 3) direitos fundamentais. (CANOTILHO, José Joaquim. Direito Constitucional e Teorias da Constituição, p. 359 e ss.).
}

outras palavras, os direitos fundamentais impõem limites ao Estado, protegendo os indivíduos e as minorias. ${ }^{3}$

De outro passo, deve-se destacar que "direitos e garantias fundamentais" (epígrafe do Título II) consiste no gênero, de que são espécies: os direitos e deveres individuais e coletivos (Capítulo I), os direitos sociais (Capítulo II), os direitos à nacionalidade (Capítulo III), os direitos políticos (Capítulo IV) e partidos políticos (Capítulo V).

Sobre a tradicional divisão dos direitos humanos em gerações ${ }^{4}$, idealizada por Karel Vasak, a mesma tem por finalidade permitir uma análise de sua amplitude, além de uma ampla compreensão sobra a causa de seu surgimento e seu contexto. De acordo com o referido jurista, a primeira geração dos direitos humanos seria a dos direitos civis e políticos, fundamentados na liberdade (liberté). A segunda geração, por sua vez, seria a dos direitos econômicos, sociais e culturais, baseados na igualdade (égalité). Por fim, a última geração seria a dos direitos de solidariedade, em especial que abarca os direitos difusos, coroando a tríade com a fraternidade (fraternité).

\section{Direitos Fundamentais Indígenas - Direito Fundamental à Preservação da Cultura Indígena}

Historiadores afirmam que antes da chegada dos europeus à América havia aproximadamente 100 milhões de índios no continente. Só em território brasileiro, esse número chegava cinco milhões de nativos, aproximadamente. Atualmente, calcula-se que apenas 400 mil índios ocupam o território brasileiro, principalmente em reservas indígenas demarcadas e protegidas pelo governo. São cerca de 200 etnias indígenas e 170 línguas. Porém, o contato com o "homem branco" fez com que muitas tribos perdessem sua identidade cultural. 
${ }^{3}$ Os direitos fundamentais protegem a minoria da maioria eventualmente eleita no sentido de que amparam os que votaram e perderam, e os que não puderam votar ou não votaram. (MIRANDA, Francisco Pontes de. Democracia, Liberdade, Igualdade: Os Três Caminhos. Campinas: Bookseller, 2001. p. 37-38).

4Tal análise perde um pouco de seu sentido quando o enfoque recai sobre os países ditos novos, como o Brasil e a Austrália, pois a maioria dos tipos de direitos humanos foram reconhecidos, logo disciplinados, de uma só vez em suas respectivas Constituições. Mas quando a análise leva em conta os países europeus, por exemplo, entende-se muito bem que o reconhecimento dos direitos humanos é um processo que perpassa vários séculos. Assim, os direitos civis apareceram no século XVIII para garantir a liberdade do indivíduo perante o Estado (opressor). Essa maior liberdade permitiu uma atuação mais ativa por parte das pessoas, o que eclodiu no reconhecimento dos direitos políticos no século XIX, ou seja, esse direito, antes exclusivo de poucos, foi estendido para grande parcela da população masculina, incluindo os trabalhadores. E o exercício desses direitos políticos, sobretudo pela classe trabalhadora, permitiu a constituição dos direitos sociais no século XX. (MARSHALL, Thomas. Cidadania, classe social e status. Rio de Janeiro: Zahar, 1967. p.57 a 114).

Ao longo dos mais de cento e oitenta anos de história, as constituições brasileiras foram representativas dos anseios das elites, com uma visão preponderantemente eurocêntrica na condução dos aspectos políticos, econômicos e culturais. Os povos indígenas sempre foram um segmento historicamente excluído da sociedade.

A preservação da cultura indígena, assim como a preservação da cultura dos diferentes grupos formadores da sociedade brasileira, foi uma preocupação trazida pelo constituinte de 1988. A Constituição inovou ao dedicar um capítulo especial à proteção dos direitos e garantias indígenas, tais como: o direito à preservação da própria cultura (artigos $255, \S 1^{\circ}, 231$, caput, $242, \S 1^{\circ}$ da $\mathrm{CF} / 88$ ); o direito à educação na própria língua (artigo 210 , $\S 2^{\circ}$, da $\mathrm{CF} / 88$ ); o direito à posse das suas terras e ao usufruto das riquezas do solo, dos rios e dos lagos nelas existentes (artigo 231, caput e $\S 2^{\circ}$, da $\mathrm{CF} / 88$ ); à proteção direta do Ministério Público na defesa desses direitos e interesses (artigo 232, da CF/88).

Art. 210. Serão fixados conteúdos mínimos para o ensino fundamental, de maneira a assegurar formação básica comum e respeito aos valores culturais e artísticos, nacionais e regionais.

(...)

$\S 2^{\circ}$ - O ensino fundamental regular será ministrado em língua portuguesa, assegurada às comunidades indígenas também a utilização de suas línguas maternas e processos próprios de aprendizagem.

(...)

Art. 215. O Estado garantirá a todos o pleno exercício dos direitos culturais e acesso às fontes da cultura nacional, e apoiará e incentivará a valorização e a difusão das manifestações culturais.

$\S 1^{\circ}$ - O Estado protegerá as manifestações das culturas populares, indígenas e afro-brasileiras, e das de outros grupos participantes do processo civilizatório nacional.

(...)

Art. 231. São reconhecidos aos índios sua organização social, costumes, línguas, crenças e tradições, e os direitos originários sobre as terras que tradicionalmente ocupam, competindo à União demarcá-las, proteger e fazer espeitar todos os seus bens.

(...)

Art. 232. Os índios, suas comunidades e organizações são partes legítimas para ingressar em juízo em defesa de seus direitos e interesses, intervindo o Ministério Público em todos os atos do processo. 


\section{(...)}

Art. 242. O princípio do art. 206, IV, não se aplica às instituições educacionais oficiais criadas por lei estadual ou municipal e existentes na data da promulgação desta Constituição, que não sejam total ou preponderantemente mantidas com recursos públicos.

$\S 1^{\circ}$ - O ensino da História do Brasil levará em conta as contribuições das diferentes culturas e etnias para a formação do povo brasileiro.

$(\ldots)^{5}$. ${ }^{5}$ BRASIL.COnstituição da República Federativa do Brasil. Disponível em: http://www.planalto.gov.br/
ccivil_03/Constituicao/Constituiçao.htm. Acesso em: 12 de outubro de 2014 .

Como se depreende pelos dispositivos supracitados, a Constituição de 1988 incluiu em seu texto os diferentes grupos formadores da sociedade brasileira e deixou claro sua importância como elemento do patrimônio cultural e sujeito a tutela do Estado. O constituinte teve, portanto, a preocupação de ver reconhecida a pluralidade de etnias e culturas.

O artigo 231 reconhece a organização social, costumes, línguas, crenças e tradições dos índios, com o que reconhece a existência de minorias nacionais e institui normas de proteção de sua singularidade étnica, especialmente de suas línguas, costumes e usos.

O objetivo do constituinte de 1988 foi de substituir o tradicional conceito formal da igualdade, que defende tratar a todos por igual, desconsiderando situações concretas de desvantagem social nas quais algumas pessoas se encontram (como os indígenas, por exemplo), passando a prever uma concepção material da igualdade, que estabelece tratar os iguais como iguais e os desiguais como desiguais. Nesse sentido, o Ministro Joaquim Barbosa Gomes, (2002, p. 4) assinala que:

Como se vê, em lugar da concepção "estática" da igualdade extraída das revoluções francesa e americana, cuida-se nos dias atuais de se consolidar a noção de igualdade material ou substancial, que, longe de se apegar ao formalismo e à abstração da concepção igualitária do pensamento liberal oitocentista, recomenda, inversamente, uma noção "dinâmica", "militante" de igualdade, na qual necessariamente são devidamente pesadas e avaliadas as desigualdades concretas existentes na sociedade, de sorte que as situações desiguais sejam tratadas de maneira dessemelhante, evitando-se assim o aprofundamento e a perpetuação de desigualdades engendradas pela própria sociedade. Produto do Estado Social de Direito, a igualdade substancial ou material propugna redobrada atenção por parte do legislador e dos aplicadores do Direito à variedade das situações individuais e de grupo, de modo a impedir que o dogma liberal da igualdade formal impeça ou dificulte a proteção e a defesa dos interesses das pessoas socialmente fragilizadas e desfavorecidas.

Dessa forma, reconhece-se constitucionalmente a diversidade cultural brasileira e "cultura" pode ser conceituada como o modo como um grupo de pessoas pensa, crê, 
vive e a forma como faz as coisas ou, ainda, o conjunto de entendimentos, crenças e conhecimentos pertencentes a determinado grupo.

No artigo 216, caput, a Constituição indica os elementos que constituem o patrimônio cultural, no caso, os bens de natureza material e imaterial, tomados individualmente ou em conjunto, portadores de referência à identidade, à ação, à memória dos diferentes grupos formadores da sociedade brasileira, nos quais se incluem: I - as formas de expressão; II - os modos de criar, fazer e viver; III - as criações científicas, artísticas e tecnológicas; IV - as obras, objetos, documentos, edificações e demais espaços destinados às manifestações artístico-culturais; V - os conjuntos urbanos e sítios de valor histórico, paisagístico, artístico, arqueológico, paleontológico, ecológico e científico.

Essas diversas formas de manifestação cultural têm em comum a exigência de que sejam observadas a identidade, a ação e a memória dos diferentes grupos formadores da sociedade brasileira. Essa exigência se coaduna com o princípio da dignidade da pessoa humana, que garante ao indivíduo a preservação das suas práticas culturais.

A consideração do direito fundamental à preservação da cultura indígena traz à tona a discussão que envolve os direitos fundamentais enumerados e direitos fundamentais não enumerados.

Nesse sentido, o art. $5^{\circ} \S 2^{\circ}$ dispõe que são direitos fundamentais os que se encontram expressos em seu texto. Entretanto, o mesmo dispositivo prevê a possibilidade da existência de direitos fundamentais não expressos na Constituição, mas decorrentes dos princípios ou do regime por ela adotado, assim como aqueles contidos em tratados internacionais dos quais o Estado brasileiro seja parte. ${ }^{6}$

Dessa forma, o rol do artigo $5^{\circ}$ é considerado numerus apertus, ou seja, o aspecto não exaustivo dos direitos e garantias fundamentais permite a defesa dos direitos indígenas, que inclui o direito à preservação da cultura indígena, como direitos fundamentais protegidos pela ordem constitucional brasileira.

Assim, segundo dispõe Vieira de Andrade (2001, p. 102-103) ao se referir à ordem constitucional portuguesa, pode-se dizer que "a definição do estatuto dos indivíduos através do reconhecimento ou da concessão de direitos fundamentais tem como escopo proteger a dignidade da pessoa humana, e que se realiza mediante a previsão e proteção de aspectos específicos da existência e da atividade humana, referindo-se, ora a sua dimensão individual (solitária), ora a seu aspecto social (solidária), muitas vezes abrangendo a complexa rede de relações interindividuais". 
Tem-se, portanto, o princípio da dignidade da pessoa humana como fundamento da ordem constitucional dos direitos fundamentais.

Outros aspectos também devem ser considerados, como a localização dos direitos fundamentais na Constituição (após o preâmbulo e os princípios fundamentais), indicando que os mesmos servem de referência para toda a ordem constitucional; a

6 No mesmo sentido: "Trata-se de evidente cláusula de abertura do rol de direitos fundamentais, a permitir a inclusão de outros direitos e garantias àqueles já previsto na Lei Maior, desde que consoantes com os princípios constitucionais. (WEIS, Carlos. Estudo sobre a obrigatoriedade de apresentação imediata da pessoa presa ao juiz: comparativo entre as previsões de tratados de direitos humanos e do projeto de Código de Processo Penal. Defensoria Pública do Estado de São Paulo, 2011.p.7).

determinação de que as normas definidoras dos direitos e garantais fundamentais têm aplicação imediata (artigo $5^{\circ}, \S 1^{\circ}, \mathrm{CF}$ ), ou seja, o julgador pode aplicar diretamente os direitos fundamentais, sem necessidade de qualquer lei que os regulamente; e a inclusão dos direitos e garantias fundamentais como cláusulas pétreas.

\section{Análise da Decisão Paradigma à luz da Constituição Federal e da Supralegalidade dos Tratados Internacionais de Direitos Humanos}

Por vinte e um anos, o Brasil passou por um período amargo da ditadura militar que, além de remoção dos direitos e garantias fundamentais, usou a força e a violência para impor sua ideologia e violar os direitos humanos em proporções graves. A crueldade e maldade usadas pelos agentes da repressão contra os opositores do regime deixaram marcas profundas na sociedade.

Durante o período da ditadura militar, com o avanço das frentes de expansão econômica em terras indígenas para a abertura de estradas, a população indígena sofreu graves violações dos direitos humanos. As terras indígenas que deveriam ser protegidos pelo Estado foram atacadas por ele. O resultado foi o extermínio de diversas etnias e o genocídio de populações inteiras indígenas. ${ }^{7} \mathrm{O}$ avanço das forças armadas nos territórios indígenas provocou também desestruturação étnica dos povos indígenas, à homogeneização de culturas, à divisão de territórios e tensões entre etnias indígenas, em uma nítida afronta ao princípio da dignidade da pessoa humana, fundamento constitucional. 
${ }^{7}$ Ao ser aberta no território dos Paraná ou Kren-Akrôro (MT/PA), a Cuibá-Santarém (BR-163) levou o extermínio de quase todo o grupo contactado em 1973 quando somava entre 300 e 600 pessoas. Dois anos depois - devido às doenças adquiridas no contato com os construtores da estrada - estava reduzido a 79 indivíduos. Ao mesmo tempo, a construção da Manaus-Caracaraí (BR-174) causava a dizimação de parte dos Waimiri-Atroari (AM), à época considerado "arredio". Hábeis guerreiros, inicialmente conseguiram impedir o avanço da estrada fustigando com arcos e flechas os tratores da obra, mas não resistiram às epidemias levadas pelas frentes de trabalhadores. De 6.000 indivíduos em 1968, o grupo ficou reduzido a 400 pessoas menos de 20 anos depois. Também na mesma época, a Perimetral Norte (BR-210) causava o desaparecimento de 20 malocas comunais Yanomami que, no contato, foram dizimados por doenças como a malária, a gripe e a tuberculose. Não se poderia deixar de mencionar também as consequências da Transamazônica (BR-230). Atravessando os estados da Paraíba, Piauí, Maranhão, Pará e Amazonas, o traçado da rodovia, inaugurada em agosto de 1972, viria a atingir mais de 20 povos indígenas, como os Parintintin (AM), Pirahã (AM), Tenharim (AM), Munduruku (PA), Arara (PA), Assurini (PA), Juruna (PA), Karahô (PA), Parakanã (PA) e Apinajé (TO), muitos dos quais vivendo ainda isoladas quando tratores passaram a rasgar as terras em que viviam. As consequências, como se poderia imaginar, foram desastrosas para tais povos. (Lacerda, Rosane. Os povos indígenas e a Constituinte - 1987/1988. Conselho Indigenista Missionário, 2008.p. 19-20).

Em 2014, o Ministério Público Federal no Amazonas ajuizou uma Ação Civil Pública (0000243-88.2014.4.01.3200), com o objetivo de obter provimento jurisdicional que declare a responsabilidade civil da União e da FUNAI por supostas violações a direitos humanos dos povos indígenas kagwahiva, Tenharim e Jiahui em decorrência dos danos socioculturais permanentes decorrentes da construção da Rodovia Transamazônica (BR-230) em seus territórios.

$\mathrm{Na}$ petição inicial, os elementos de prova trazidos pelo Ministério Público demonstram que a construção rodovia causou danos de ordem sociocultural, dentre os quais atesta que a obra causou prejuízos a locais e territórios sagrados dos povos indígenas. O Ministério Público explica que antes da construção da rodovia, os índios Tenharim viviam em uma aldeia situada na margem direita do Rio Marmelos, em local chamado São José. Porém, após a obra, os índios passaram a habitar as margens da rodovia (e não outro lugar mais distante do traçado da rodovia), pois sentiram a necessidade de permanecerem próximos aos seus locais sagrados. Em decisão liminar, o Juiz Federal, assim decidiu:

De fato, a maior parte dos argumentos apresentados na petição inicial referem-se aos danos decorrentes da construção da Rodovia Transamazônica, na década de 1970. Em razão destes danos, o MPF pleiteia a adoção de medidas inibitórias e reparatórias, tendentes a minimizar os prejuízos supostamente sofridos pelos povos indígenas Tenharim e Jiahui em razão desta obra. (...) Na inicial, o MPF defende a necessidade de adoção de medidas de reparação aos danos causados pela construção da Rodovia Transamazônica aos índios Tenharim e Jiahui, em razão de ter atravessado suas áreas de ocupação tradicional, causando danos de 
natureza ambiental e sociocultural. Os elementos de prova trazidos pelo Ministério Público, na petição inicial, constituem prova robusta de suas alegações. Traz laudo elaborado pelo Analista em Antropologia Walter Coutinho Junior, que de forma fundamentada relata as consequências advindas para os povos indígenas em decorrência da construção da rodovia (fls. 33-68). Acompanha a inicial também estudo realizado por Maria Schulz, que também relata os efeitos causados pela obra em questão (fls. 189-250). Na inicial, o MPF relata que a construção rodovia causou danos de ordem sociocultural, dentre os quais refere que obra causou prejuízos a locais e territórios sagrados dos povos indígenas. Refere que, antes da construção da rodovia, os índios Tenharim viviam em aldeia situada na margem direita do Rio Marmelos, em local chamado São José.

E continua o ilustre julgador:

A Constituição é expressa ao assegurar aos índios a preservação de sua organização social, costumes, línguas, crenças e tradições (art. 231). Ademais, não só aos índios, mas a todos os cidadãos assegura-se também a liberdade religiosa, com necessidade de proteção, pelo Estado, dos locais de culto e suas liturgias (art. $5^{\circ}, \mathrm{VI}$ ). Ressalto que o Brasil aderiu à Convenção n. 169 da Organização Internacional do Trabalho, sobre Povos Indígenas

e Tribais, promulgando-a através do Decreto n. 5.051/2004. Prevê-se expressamente ser dever estatal reconhecer e proteger os valores e práticas sociais, culturais, religiosas e espirituais dos povos indígenas (art. 50, "a"). Determina, ainda, que os governos deverão respeitar a importância especial que para as culturas e valores espirituais dos povos interessados possui a sua relação com as terras ou territórios (art. 13, 1). Assim, é dever do Estado assegurar proteção aos locais sagrados dos povos indígenas, estando demonstrado que a passagem da rodovia pelas terras ocupadas pelos povos tenharim e jiahui trouxe perturbação a tais áreas.

Pela análise das provas colacionadas aos autos, não restam dúvidas de que a construção da rodovia causou danos de natureza socioculturais e que cabe ao Estado providenciar medidas de reparação. Verifica-se que a decisão tomada pelo magistrado se coaduna tanto com os ditames estabelecidos pela ordem constitucional (direitos fundamentais), como pelas regras firmadas em pactos internacionais (direitos humanos). O ilustre magistrado fundamenta sua decisão tanto nos dispositivos constitucionais que protegem a preservação da cultura indígena (art. 231, CF), como na Convenção $\mathrm{n}^{\circ} 169$ da Organização Internacional do Trabalho, sobre Povos Indígenas e Tribais, promulgando através do Decreto n. 5.051/2004.

Nesse contexto, cumpre esclarecer sobre o relacionamento do direito internacional com o nacional. Segundo a tese monista, o direito internacional e o nacional fazem parte do mesmo sistema jurídico, ou seja, incidem sobre o mesmo espaço. De outro passo, a tese dualista defende que cada qual pertence a um sistema distinto e, por assim dizer, incidem sobre aspectos diversos.

O dualismo se subdivide em dualismo radical, que impõe a edição de uma lei distinta para a incorporação dos tratados internacionais; e em dualismo moderado ou 
temperado, que exige apenas um procedimento formal. Como a Constituição Federal silenciou sobre esse aspecto, a doutrina aponta que o Brasil adotou a corrente dualista moderada, haja vista que os tratados internacionais só terão validade interna após aprovação pelo Congresso Nacional e ratificação e promulgação pelo presidente da República.

Com a edição da $\mathrm{EC} \mathrm{n}^{\circ} 45$, os tratados de direitos humanos que forem aprovados em cada Casa do Congresso Nacional, em dois turnos, por três quintos dos votos dos respectivos membros, serão equivalentes às emendas constitucionais ${ }^{8}$ - conforme o que

\footnotetext{
${ }^{8}$ Também rompe a harmonia do sistema de integração dos tratados de direitos humanos no Brasil, uma vez que cria categorias jurídicas entre os próprios instrumentos internacionais de direitos humanos ratificados pelo governo, dando tratamento diferente para normas internacionais que têm o mesmo fundamento de validade, ou seja, hierarquizando diferentes tratados que têm o mesmo conteúdo ético, qual seja a proteção internacional dos direitos humanos. Assim essa desigualação dos desiguais que permite o $\S 3^{\circ}$ ao estabelecer
}

determina o $\S 3^{\circ}$ do artigo $5^{\circ}$ da $\mathrm{CF}$. Ou seja, tais tratados terão hierarquia constitucional quando aprovados por maioria qualificada no Congresso Nacional e forem ratificados e posteriormente publicados pelo presidente da República.

Importante ressaltar que cabe ao Congresso Nacional decidir quando aprovará o tratado internacional de direitos humanos pelo quórum especial. Ou seja, trata-se de poder discricionário, pois ele não tem o dever de sempre aprovar os tratados de direitos humanos pela maioria qualificada.

Muito se discutiu em relação à hierarquia dos tratados de direitos humanos que foram internacionalizados anteriormente à edição da EC n. ${ }^{\circ}$ 45. Em 3 de dezembro de 2008, o Ministro do STF, Gilmar Mendes, no julgamento do RE 466-343-SP, defendeu a tese da supralegalidade de tais tratados, ou seja, superior às normas infraconstitucionais e inferior às normas constitucionais. $\mathrm{O}$ voto do Ministro Gilmar Mendes foi acompanhado pela maioria (posição atual do STF). Portanto, todo tratado de direitos humanos que foi internalizado sem observar o procedimento estabelecido no artigo $5^{\circ}, \S^{\circ}$ da $\mathrm{CF}$, tem status de norma supralegal. Nesse sentido explica Antonio Moreira Maués (2013):

A posição adotada pela maioria do STF, no entanto, foi a tese da supralegalidade. Dentre as razões apresentadas em favor dessa decisão, podemos destacar: a) a supremacia formal e material da Constituição sobre todo o ordenamento jurídico, consubstanciada na possibilidade de controle de constitucionalidade inclusive dos diplomas internacionais; b) o risco de uma ampliação inadequada da expressão "direitos humanos", que permitiria uma 
produção normativa alheia ao controle de sua compatibilidade com a ordem constitucional interna; c) o entendimento que a inclusão do parágrafo $3^{\circ}$ do artigo $5^{\circ}$ implicou reconhecer que os tratados ratificados pelo Brasil antes da $\mathrm{EC} \mathrm{n}^{\circ} 45$ não podem ser comparados às normas constitucionais.

Apesar da tese da supralegalidade ser um avanço da jurisprudência brasileira, tal assunto desperta calorosas discussões, haja vista que no mesmo recurso extraordinário em que foi exarada a tese da supralegalidade, o Ministro Celso de Mello defendeu o caráter constitucional dos tratados de direitos humanos independentemente do quórum de aprovação. No mesmo sentido, há doutrina que defende que os tratados direitos humanos internacionalizados sem o procedimento especial, teriam status constitucional, haja vista o disposto no $\S 2^{\circ}$ que inclui os direitos humanos provenientes de tratados entre seus

ditas categorias de tratados é totalmente injurídica por violar o princípio (também constitucional) da isonomia. (MAZZUOLI, Valério de Oliveira. O controle jurisdicional da convencionalidade das leis. $2^{\mathrm{a}}$ Ed. São Paulo: Revista Jurídica Consulex, 2009. p. 29).

direitos protegidos, o que ampliaria o bloco de constitucionalidade. Observa-se como preleciona Valério Mazzuoli:

Da análise do $\S 2^{\circ}$ do artigo $5^{\circ}$ da Carta brasileira de 1988 , percebe-se que três são as vertentes, no texto constitucional brasileiro, dos direitos e garantias fundamentais individuais: a) direitos e garantias expressos na Constituição, a exemplos dos elencados nos incisos I a LXXVIII do seu art. $5^{\circ}$, bem como outros fora do rol de direitos, mas dentro da Constituição, como a garantia da anterioridade tributária, prevista no artigo 150, III, b, do Texto Magno; b) direitos e garantias implícitos, subtendidos nas regras de garantias, bem como os decorrentes do regime e dos princípios pela Constituição adotados, e c) direitos e garantias inscritos nos tratados internacionais em que a República Federativa do Brasil seja parte.

E continua o supracitado jurista:

O que se deve entender é que o quórum que o $\$ 3^{\circ}$ do art. $5^{\circ}$ estabelece serve tão somente para atribuir eficácia formal a esses tratados no nosso ordenamento jurídico interno, e não para atribuir-lhes a índole e o nível materialmente constitucionais que eles já têm em virtude $\S 2^{\circ}$ do artigo $5^{\circ}$ da Constituição.

Ingo Sarlet (2006), comungando deste mesmo entendimento, leciona que:

De qualquer modo, não nos parece correto argumentar - notadamente em favor da inconstitucionalidade substancial do $\S 3^{\circ}$ do art. $5^{\circ}$ - que o simples fato de os tratados posteriores à EC 45 poderem (ou deverem, a depender da posição adotada) ser aprovados por emenda constitucional, conduziria, inexoravelmente a uma decisão em prol da hierarquia meramente legal dos tratados anteriores. No tocante a este ponto, consideramos estar diante de um falso problema, visto que, como já demonstrado, a nova disposição introduzida pela EC 45 pode ser compreendida como reforçando o entendimento de que os tratados anteriores, já por força do art. $5^{\circ}, \S 2^{\circ}$, da $\mathrm{CF}$, possuem hierarquia materialmente 
constitucional, sem falar na interpretação - igualmente colacionada, mas aqui questionada - de acordo com a qual os tratados anteriores teriam sido recepcionados como equivalentes às emendas constitucionais pelo novo $\S 3^{\circ}$ do art. $5^{\circ}$. Pelo menos, se em tese é possível que o entendimento adotado pelo Supremo Tribunal Federal seja o da manutenção de sua jurisprudência atual, no sentido da hierarquia legal dos tratados, não o será necessariamente em virtude do teor do $\S 3^{\circ}$ do art. $5^{\circ}$, já que a tese da paridade entre lei e tratado é anterior.

Com relação à Convenção 169 da OIT, esta foi ratificada pelo Decreto Legislativo $n^{\circ} 143$, de 20/6/2002, e entrou em vigor em 2003, ou seja, antes da edição da EC $\mathrm{n}^{\mathrm{o}} 45$, o que lhe confere hierarquia intermediária, na medida em que são inferiores às normas constitucionais, mas necessariamente interpretadas como superiores às normas ordinárias, ou seja, possui o status de supralegal.

Ademais, MAUÉS (2013) defende que independentemente da posição hierárquica que o tratado assuma, o Estado brasileiro tem o dever de cumpri-lo, harmonizando as disposições estabelecidas no tratado com as disposições internas, especialmente as de caráter constitucional, haja vista que tanto os direitos fundamentais, como os direitos humanos, possuem a função limitadora do poder coercitivo estatal. Alerta ainda o autor sobre a possibilidade que os tratados de direitos humanos sejam utilizados não só para interpretar as disposições legais, mas também a própria Constituição.

Sendo assim, cabe verificar a validade de uma lei (e sua consequente eficácia) não só com a Constituição Federal (controle de constitucionalidade), mas também compatibilizá-la com os tratados internacionais de direitos humanos em vigor no Brasil, o que se denomina de controle de convencionalidade. Sobre o tema, MAZZUOLI (2009, p. 74) esclarece:

Em suma, doravante se falará em controle de constitucionalidade apenas para o estrito caso de (in) compatibilidade vertical das leis com a Constituição, e em convencionalidade para os casos de (in) compatibilidade legislativa com os tratados de direitos humanos (formalmente constitucionais ou não) em vigor no país.

Portanto, criou-se um controle material de validade ${ }^{9}$ da legislação interna. Em termos gerais, MAZZUOLI (2009) defende que a legislação interna deverá ser confrontada por dois limites materiais verticais: primeiro pela Constituição (controle de constitucionalidade) e pelos tratados de direitos humanos que possuam natureza constitucional (controle de convencionalidade); e depois pelos demais tratados que 
possuam status supralegal (controle de supralegalidade). Como ele coloca (MAZZUOLI, 2009, p. 136):

O controle de supralegalidade é sempre exercido pela via de exceção, ou seja, é sempre difuso, já o controle de convencionalidade poderá ser difuso ou concentrado, neste último caso quando o tratado de direitos humanos for aprovado pela sistemática do art. $5^{\circ}, \S 3^{\circ}$, da Constituição e entrar em vigor no Brasil (entende-as após ratificado) com a equivalência de emenda constitucional.

Percebe-se, portanto, que o controle de convencionalidade proporciona o fenômeno chamado doutrinariamente de ampliação de parametricidade constitucional .

\footnotetext{
${ }^{9}$ Em suma, a validade das normas jurídicas, nesse novo contorno que o constitucionalismo contemporâneo lhe traz, não é mais uma conotação meramente formal, a depender somente da regularidade do seu processo de produção (conforme defendido por Hobbes, posteriormente por Bentham e Austin, até chegar a Kelsen e Bobbio). Tornou-se ela também (como explica Ferrajoli) um fato substancial, dependente dos conteúdos das decisões, as quais serão inválidas se contrastarem com os novos princípios positivos do direito internacional.
}

(MAZZUOLI, Valério de Oliveira. O controle jurisdicional da convencionalidade das leis. $2^{\text {a }}$ Ed. São Paulo: Revista Jurídica Consulex, 2009. p. 105-106).

A respeito da proteção internacional dos direitos humanos, deve-se frisar que a Declaração Universal dos Direitos Humanos (DUDH) de 1948 representou um marco na proteção desses direitos, com a consagração da tese da universalidade. No entanto, a efetividade universal de suas normas continua em estágio de implementação, uma vez que houve um número limitado de países que participaram de sua elaboração, bem como pelo fato de não ter havido um consenso desde o início em relação às normas que deveriam ser positivadas.

O debate entre universalismo e relativismo cultural dos direitos humanos sempre esteve presente nos foros internacionais. De acordo com a corrente do universalismo cultural, os direitos humanos são universais e deve ser garantidos pelos estados nacionais e pela comunidade internacional em qualquer situação e contra qualquer agente violador.

Já a corrente do relativismo cultural, defende a concepção de que os Direitos Humanos são variáveis de acordo com as respectivas culturas. Os Estados nacionais e a comunidade internacional devem protegê-los, mas respeitando a autonomia dos povos em determinar suas próprias práticas culturais (Principio da auto-determinação dos povos). Não se pode admitir a intervenção estatal, porque a concepção de direitos humanos é variável de acordo com a cultura. 
O que poderia superar as duas posições polares poderia ser a teoria do multiculturalismo que é o reconhecimento das diferentes culturas. Segundo Lopes (2007), o Multiculturalismo é a teoria que defende a valorização da cultura dos diversos grupos que compõem a humanidade, que defende que ser diferente não significa ser nem melhor nem pior do que ninguém, que é contra a uniformização ou padronização do ser humano, que valoriza as minorias e suas especificidades e que entende que o mais valioso que tem a humanidade é a sua diversidade.

\section{Conclusão}

A partir da argumentação exposta e da decisão colacionada, pode-se concluir que os direitos humanos são "direitos válidos para todos os povos e em todos os tempos", ao passo que os direitos fundamentais são direitos garantidos na constituição com limitação espacial e em um dado período de tempo.

Como o rol do artigo $5^{\circ}$ da Constituição Federal de 1988, é considerado numerus apertus, ou seja, não exaustivo dos direitos e garantias fundamentais, permite a defesa dos direitos indígenas, que inclui o direito à preservação da cultura indígena, como direitos fundamentais protegidos pela ordem constitucional brasileira. No âmbito da proteção internacional dos direitos humanos, merece destaque a teoria do multiculturalismo que valoriza a cultura das minorias e suas especificidades.

Sobre o status dos tratados internacionais, o STF defende a tese da supralegalidade de tais tratados, ou seja, superior às normas infraconstitucionais e inferior às normas constitucionais. Dessa forma, a legislação infraconstitucional deve ser compatível tanto com a Constituição Federal como com os tratados internacionais de direitos humanos ratificados pelo Estado, possibilitando a construção de um Estado Constitucional e Humanista de Direito, que tem por princípio a prevalência dos direitos humanos.

\section{REFERÊNCIAS}

ALEXY, Robert. Teoria dos Direitos Fundamentais. Tradução Virgílio Afonso da Silva. São Paulo: Malheiros, 2008. 
BARCELLOS, Ana Paula de. A eficácia dos princípios constitucionais: o princípio da dignidade da pessoa humana. Rio de Janeiro: Renovar, 2002.

BARROSO, Luís Roberto. O Direito Constitucional e a Efetividade de suas Normas. Limites e possibilidade da Constituição brasileira. Rio de Janeiro: Renovar, 2006.

BIAGI, Cláudia Perotto. A garantia do conteúdo essencial dos direitos fundamentais na jurisprudência constitucional brasileira. Porto Alegre: Sergio Antonio Fabris Ed., 2005.

BIDART CAMPOS, Germán J. Teoría General de los Derechos Humanos. Buenos Aires: Astrea, 1992.

BOBBIO, Norberto. A era dos direitos. Rio de Janeiro: Campus, 1992.

BOBBIO, Norberto. O futuro da democracia: Uma defesa das regras do jogo. Rio de Janeiro: Paz e Terra, 2000.

BRASIL. Constituição (1988). Constituição da República Federativa do Brasil. Brasília, DF, Senado, 1988.

CANOTILHO, Joaquim José Gomes. Direito Constitucional e Teorias da Constituição. $3^{\text {a }}$ ed., Coimbra: Almedina, 1999.

CANOTILHO, José Joaquim Gomes. Estudo sobre direitos Fundamentais. $1^{\text {a }}$ ed., São Paulo: Editora Revista dos Tribunais; Portugal: Coimbra Editora, 2008.

COMPARATO, Fábio Konder. Muda Brasil: uma constituição para o desenvolvimento democrático. Editora Brasiliense: São Paulo, 1986.

DALLARI, Dalmo de Abreu. Direitos humanos e cidadania. São Paulo: Moderna, 1998.

FACCHINI NETO, Eugênio. Reflexões histórico-evolutivas sobre a constitucionalização do direito privado. SARLET, Ingo Wolfgang (Org.). In: Constituição, Direitos Fundamentais e Direito Privado. Porto Alegre: Livraria do Advogado Editora, 2003.

FAUSTO, Boris. História do Brasil. 6. ed. São Paulo: USP, 1999.

FURTADO, Emmanuel Teófilo. Preconceito e discriminação por idade. São Paulo: LTR, 2004.

GARZON, Biviany Rojas (Org,). Convenção 169 da OIT sobre povos indígenas e tribais. Oportunidades e desafios para sua implementação no Brasil. São Paulo: Instituto Sócio Ambiental, 2009.

GOMES, Joaquim Barbosa. O debate constitucional sobre as ações afirmativas. Site Mundo Jurídico, Rio de Janeiro. Disponível em: <http://www.mundojuridico.adv.br>. Acesso em: 12 de outubro de 2014. 
ISRAEL, Jean Jacques. Direito das liberdades fundamentais. Tradução Carlos Souza. Barueri: Manole, 2005.

LACERDA, Rosane. Os povos indígenas e a Constituinte - 1987/1988. Brasília:

Conselho Indigenista Missionário, 2008.

LEDUR, José Felipe. Direitos Fundamentais Sociais: efetivação no âmbito da democracia participativa. Porto Alegre: Livraria do Advogado Editora, 2009.

LOPES, Ana Maria D’Ávila. Hierarquização dos direitos fundamentais? Revista de Direito Constitucional e Internacional, São Paulo, v. 9, n. 34, p. 168-183, 2001.

LOPES, Ana Maria D’Ávila. A contribuição da teoria do multiculturalismo para a defesa dos direitos fundamentais dos indígenas brasileiros. XV Congresso Nacional do CONPEDI, 2007, Manaus. Disponível em: <http://www.conpedi.org/manaus/arquivos/anais/manaus/estado_dir_povos_ana_maria_ lopes.pdf >. Acesso em: 20/10/2014.

LOPES, Ana Maria D’Ávila. MATTOS, Karine Rodrigues. O direito fundamental dos indígenas à terra: uma investigação científica do Brasil Colônia ao Estado Democrático de Direito. Revista de Informação Legislativa, v. 43, p. 221-234, Brasília: Senado Federal, 2006, p. 222.

LOPES, Ana Maria D'Ávila. Os direitos fundamentais como limites ao poder de legislar. Porto Alegre: Sérgio Fabris, 2001.

LOPES, Ana Maria D'Ávila. Democracia hoje. Para uma leitura crítica dos direitos fundamentais. Passo Fundo: Universidade de Passo Fundo, 2001.

LUÑO, Antonio Enrique Pérez. Derechos Humanos, Estado de Derecho e Constitución. 5 ed. Madrid: Tecnos, 2007.

LUÑO, Antonio Enrique Pérez. Los Derechos fundamentales, Madrid: Tecnos, 1995.

MARSHALL, Thomas. Cidadania, classe social e status. Rio de Janeiro: Zahar, 1967. p. 57 a 114.

MAUÉS, Antônio. Moreira. Supralegalidade dos Tratados Internacionais de Direitos Humanos e Interpretação Constitucional. Revista Internacional de Direitos Humanos.

2013.

Disponível

em

http://www.surjournal.org/conteudos/getArtigo18.php?artigo=18,artigo_11.htm

MAZZUOLI, Valério de Oliveira. O controle jurisdicional da convencionalidade das leis. $2^{\text {a }}$ Ed. São Paulo: Revista Jurídica Consulex, 2009.

MELLO, Celso Antônio Bandeira de. O Conteúdo Jurídico do Princípio da Igualdade.

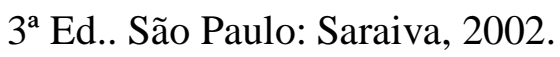


MIRANDA, Francisco Pontes de. Democracia, Liberdade, Igualdade: Os Três Caminhos. Campinas: Bookseller, 2001.

NUNES, Anelise Coelho. A titularidade dos direitos fundamentais na Constituição Federal de 1988. Porto Alegre: Livraria do Advogado Editora, 2007.

OBSERVATÓRIO INDÍGENA. Violações dos direitos indígenas. Educação. Disponível em: http://www.observatorioindigena.ufc.br/oktiva.net/1983/nota/67633.Acesso em: 14 ag. 2009.

SARLET, Ingo Wolfgang. A Eficácia dos direitos fundamentais. Porto Alegre: Livraria do Advogado, 2006.

SARLET, Ingo Wolfgang. A Reforma do Judiciário e os tratados internacionais de direitos humanos: observações sobre o $\S 3^{\circ}$ do art. $5^{\circ}$ da Constituição. In: Âmbito Jurídico, Rio Grande, IX, n. 34, nov 2006. Disponível em: <http://www.ambitojuridico.com.br/site/index.php?n_link=revista_artigos_leitura\&artigo_id=1338>. Acesso em out 2014.

SARLET, Ingo Wolfgang. Dignidade da pessoa humana e direitos fundamentais na Constituição Federal de 1988. Porto Alegre: Livraria do Advogado, 2004.

SILVA, José Afonso da. A democracia e direitos humanos. In. SARLET, Ingo Wolfgang; CLÉVE, Emerson Merlin; PAGLIARINI, Alexandre Coutinho (Coordenadores). In: Direitos Humanos e Democracia. Rio de Janeiro: Forense, 2007.

SILVA, José Afonso da. A dignidade da pessoa humana como valor supremo da democracia. Revista de Direito Administrativo, Rio de Janeiro, n. 212, p. 88-94, Abr./Jul. quadrimestral. 1998. 
TRINDADE, Antônio Augusto Cançado. Tratado de direito internacional dos direitos humanos. 2. ed. Porto Alegre: Sergio Antonio Fabris, 2003, v.1. p. 305.

VIEIRA DE ANDRADE, José Carlos. Os Direitos Fundamentais na Constituição Portuguesa de 1976. $2^{\text {a }}$ edição. Coimbra, Almedina, 2001.

WEIS, Carlos. Estudo sobre a obrigatoriedade de apresentação imediata da pessoa presa ao juiz: comparativo entre as previsões de tratados de direitos humanos e do projeto de Código de Processo Penal. Defensoria Pública do Estado de São Paulo, 2011.p.7. 